\title{
Name and Version
}

National Cancer Institute

\section{Source}

National Cancer Institute. Name and Version. NCI Thesaurus. Code C156472.

An identifier that includes the words or language units by which a thing is known and the form or variant of the original. 